\title{
Low-Temperature Plasma Nitriding of Sintered PIM 316L Austenitic Stainless Steel
}

\author{
Aércio Fernando Mendes ${ }^{\mathrm{a}}$, Cristiano José Scheuer ${ }^{\mathrm{a}, \mathrm{b}}$, Ioanis Labhardt Joanidis ${ }^{\mathrm{a}}$, Rodrigo Perito Cardoso \\ Márcio Mafra ${ }^{\mathrm{a}, \mathrm{c}}$, Aloísio Nelmo Klein ${ }^{\mathrm{a}, \mathrm{d}}$, Silvio Francisco Brunatto ${ }^{\mathrm{a} *}$ \\ ${ }^{\mathrm{a}}$ Grupo de Tecnologia de Fabricação Assistida por Plasma e Metalurgia do Pó, Departamento de \\ Engenharia Mecânica, Universidade Federal do Paraná - UFPR, CEP 81531-990, Curitiba, PR, Brasil \\ ${ }^{\mathrm{b}}$ Colégio Técnico Industrial de Santa Maria - CTISM, Universidade Federal de Santa Maria - UFSM, \\ CEP 97105-900, Santa Maria, RS, Brasil \\ 'Departamento Acadêmico de Mecânica, Universidade Tecnológica Federal do Paraná-UTFPR, \\ CEP 80230-901, Curitiba, PR, Brasil \\ ${ }^{\mathrm{d}}$ Departamento de Engenharia Mecânica, Universidade Federal de Santa Catarina - UFSC, \\ CEP 88040-900, Florianópolis, SC, Brasil
}

Received: June 24, 2013; Revised: March 6, 2014

\begin{abstract}
This work reports experimental results on sintered PIM 316L stainless steel low-temperature plasma nitriding. The effect of treatment temperature and time on process kinetics, microstructure and surface characteristics of the nitrided samples were investigated. Nitriding was carried out at temperatures of $350,380,410$ and $440{ }^{\circ} \mathrm{C}$, and times of 4,8 and $16 \mathrm{~h}$, using a gas mixture composed by $60 \% \mathrm{~N}_{2}+20 \% \mathrm{H}_{2}+20 \% \mathrm{Ar}$, at a gas flow rate of $5.00 \times 10^{-6} \mathrm{Nm}^{3} \mathrm{~s}^{-1}$, and a pressure of $800 \mathrm{~Pa}$. The treated samples were characterized by scanning electron microscopy, X-ray diffractometry and microhardness measurements. Results indicate that low-temperature plasma nitriding is a diffusion controlled process. The calculated activation energy for nitrided layer growth was $111.4 \mathrm{kJmol}^{-1}$. Apparently precipitation-free layers were produced in this study. It was also observed that the higher the treatment temperature and time the higher is the obtained surface hardness. Hardness up to $1343 \mathrm{HV}_{0.025}$ was verified for samples nitrided at $440{ }^{\circ} \mathrm{C}$. Finally, the characterization of the treated surface indicates the formation of cracks, which were observed in regions adjacent to the original pores after the treatment.
\end{abstract}

Keywords: low-temperature plasma nitriding, plasma nitriding kinetics, sintered PIM 316L stainless steel, expanded austenite, surface porosity sealing, nitriding cracks

\section{Introduction}

Plasma surface treatments have been widely used in industrial applications, being extensively employed for the surface treatment of powder metallurgy components, mainly in the automotive field ${ }^{1-6}$.

The porosity and the pore size have a significant effect on powder metallurgy materials properties ${ }^{2,7,8}$. As a consequence, sintered components are more susceptible to wear, corrosion and fatigue compared with full density parts $^{4,5}$. Aiming to minimize the detrimental effects of the pores on the properties of sintered steels, surface treatments such as nitriding are commonly used in order to reduce the surface porosity of sintered parts. For this purpose, the application of plasma assisted technology has some advantages over conventional processes, such as gas or salt bath nitriding ${ }^{2}$. After salt bath treatment, a thorough cleaning of the sintered part is necessary to avoid corrosion and abrasive wear caused by the salt remaining into the pores of the material ${ }^{1,2,4,5,9}$. During gas nitriding treatment, favored by the presence of opened and connected surface pores, gas penetrates into the material bulk causing an excessive hardening penetration and swelling, so that the sintered component becomes brittle ${ }^{1,2,9}$. The plasma nitriding reduces the influence of pores on the characteristics of the modified

*e-mail: brunatto@ufpr.br layer, producing samples which present a better control of hardness and case depth ${ }^{1,2,5,10}$.

On the other hand, low-temperature plasma nitriding of austenitic stainless steels has been extensively studied, being accept in many different industry sectors, due to the formation of nitrogen-expanded austenite $\left(\gamma_{\mathrm{N}}\right)$, also called as $\mathrm{S}$ phase ${ }^{11}$. The interest in nitrogen-expanded austenite is primarily related with the significant improvement of hardness and tribological properties ${ }^{12,13}$, combined with excellent corrosion resistance ${ }^{11}$. Due to this attractive combination of properties, expanded austenite has been recognized as one the most significant recent developments in stainless steels ${ }^{14}$.

Aiming to improve the knowledge on the lowtemperature plasma nitriding of sintered PIM 316L austenitic stainless steel, the effect of nitriding temperature and time on the process kinetics, microstructure and surface characteristics of the nitride surfaces was investigated, being the results presented and discussed in the present work.

\section{Experimental Procedures}

AISI 316L austenitic stainless steel $(17 \% \mathrm{Cr}, 13.5 \% \mathrm{Ni}$, $2.5 \% \mathrm{Mo},<2 \% \mathrm{Mn},<1 \% \mathrm{Si},<0.04 \% \mathrm{C}$, and $\mathrm{Fe}$ balance, in wt.\%) PIM parts of $10.5 \times 50.0 \times 3.5 \mathrm{~mm}$ dimension 
were obtained from pre-alloyed powders mixture (70\% of water atomized powder presenting average particle size of $10 \mu \mathrm{m}$, and $30 \%$ of gas atomized powder with average particle size of $20 \mu \mathrm{m}$ ) and a polymeric resin to enable the powder injection molding (PIM) processing. After injection, the parts were submitted to two step binder extraction: a) the first one, parts were kept in hexane for 4 hours; and b) parts were heated in an oxidizing atmosphere oven for 2 hours at $140{ }^{\circ} \mathrm{C}$. Green parts were exposed to a thermal cycle in DC glow discharge comprising an oxide reduction stage at $900{ }^{\circ} \mathrm{C}$ for 0.5 hours, and sintering stage at $1200{ }^{\circ} \mathrm{C}$ for 2 hours, in a $80 \% \mathrm{Ar}+20 \% \mathrm{H}_{2}$ gas mixture. As a result, sintered parts with average relative porosity on the order of $4 \%$ were obtained. Finally, samples for plasma nitriding treatment were cut from sintered PIM parts in dimension of $10.0 \times 5.0 \times 3.0 \mathrm{~mm}$, being cleaned in an alcohol ultrasound bath before the nitriding treatment.

For cleaning purpose, before nitriding stage, specimens were plasma sputter-cleaned in a gas mixture of $80 \%$ $\mathrm{H}_{2}+20 \% \mathrm{Ar}$, under a pressure of $800 \mathrm{~Pa}$, at $300{ }^{\circ} \mathrm{C}$ for $0.5 \mathrm{~h}$. Plasma nitriding was carried out using a gas mixture composition of $60 \% \mathrm{~N}_{2}+20 \% \mathrm{H}_{2}+20 \% \mathrm{Ar}$, in volume. The total gas flow rate and pressure were fixed at $5.00 \times 10^{-6} \mathrm{Nm}^{3} \mathrm{~s}^{-1}(300 \mathrm{sccm})$ and $800 \mathrm{~Pa}$, respectively. Samples were nitrided at $350,380,410$ and $440{ }^{\circ} \mathrm{C}$ for a treatment time of $8 \mathrm{~h}$, and for 4,8 and $16 \mathrm{~h}$ at a treatment temperature of $380{ }^{\circ} \mathrm{C}$. The plasma apparatus consisted of a $4.16 \mathrm{kHz}$ squarewave pulsed DC power supply and a stainless steel cylindrical vacuum chamber of $350 \mathrm{~mm}$ in diameter and $380 \mathrm{~mm}$ high, attached to steel plates sealed with silicone o-rings at both the ends. The system was pumped down to a residual pressure on the order of $3 \mathrm{~Pa}$ using a double stage mechanical vacuum pump. The gas mixture flux of $\mathrm{N}_{2}, \mathrm{H}_{2}$, and $\mathrm{Ar}$ was adjusted by three mass flow controllers of $8.33 \times 10^{-6} \mathrm{Nm}^{3} \mathrm{~s}^{-1}$ (500 sccm). A detailed description of the plasma nitriding apparatus utilized in this work is presented in Allenstein et al. ${ }^{15}$.

Samples were placed on the cathode of the discharge, which was negatively biased at $700 \mathrm{~V}$. The heating of the samples was a result of ions and fast neutrals species bombardment. The mean power transferred to the plasma, and consequently the sample temperature, was adjusted by varying the switched-on time $\left(\mathrm{t}_{\mathrm{ON}}\right)$ of the pulsed voltage. The temperature was measured by means of a chromel alumel thermocouple (K-type of $1.5 \mathrm{~mm}$ diameter) inserted $8 \mathrm{~mm}$ depth into the sample holder. The pressure in the vacuum chamber was measured by a capacitive manometer of $1.33 \times 10^{4} \mathrm{~Pa}$ in full-scale operation and adjusted by a manual valve.

For microstructure analysis, samples were prepared by conventional metallographic procedure. After polishing, the cross-sectioned samples were etched using Marble's etchant $\left(1 \mathrm{~g} \mathrm{CuSO}_{4},+5 \mathrm{ml} \mathrm{HCl}+5 \mathrm{ml} \mathrm{H}_{2} \mathrm{O}\right)$, being kept immersed in the etchant for 10 minutes under manual agitation. Samples cross-sections were analyzed by a Jeol JSM - 6360LV scanning electron microscope. Xray diffractometry (XRD) technique was applied aiming to determine the phases present in the treated surfaces, using a Shimadzu XDR 7000 Xray diffractometer in the Bragg-Brentano configuration with a $\mathrm{Cu} K \alpha$ X-ray tube $(\lambda=0.17889 \mathrm{~nm})$ operated at
$40 \mathrm{kV}$ and $20 \mathrm{~mA}$. The diffraction lines were taken with $2 \theta$ in the range of $30-60^{\circ}$ with steps of $0.016^{\circ}$ per second. Surface hardness measurements were performed employing a Shimadzu Micro Hardness Tester HMV2T, applying a load of $25 \mathrm{gf}$ and a peak-load contact of $15 \mathrm{~s}$. The presented surface hardness values are a mean of five measurements. In order to characterize the pores present at the surface, both the surfaces in the as-sintered and as-nitrided conditions were photographed with $1000 x$ magnification, in a Philips XL30 scanning electron microscope, being that a total of five different regions of the samples were mapped, and five images for each region were obtained (these regions were delimited by scratches prior to nitriding treatment, being that only the delimitated areas were mapped by SEM after and before the nitriding treatment). The Ferret diameter was chosen to determine the average pore sizes present in both the surfaces. The results were confronted and the pore size variation was estimated, aiming to determine the efficiency of the nitriding process as a pore sealing treatment.

\section{Results and Discussion}

\subsection{Nitrided layer characterization}

The cross section micrographs of sintered PIM 316L stainless steel samples plasma nitrided at temperatures of $350,380,410$ and $440{ }^{\circ} \mathrm{C}$ are shown in Figures 1a-d, respectively. It is to be noted that the nitrided layer thickness increases for higher treatment temperatures, presenting values of $2.9 \pm 0.28,4.29 \pm 0.3,6.5 \pm 0.3$ and $11.27 \pm 1.3 \mu \mathrm{m}$ (mean of ten values measured at different layer regions), respectively. In general, the nitrided layers appear as a single homogeneous layer separated from the substrate bulk by an etched line. The homogeneous layer is the result of the nitrogen-expanded austenite phase formation $\left(\gamma_{N}\right)$. The etched line, as reported by Czerwiec ${ }^{16}$, would probably due to the carbon contamination that tends to occur during the in situ cleaning procedure in an $\mathrm{Ar}-\mathrm{H}_{2}$ glow discharge, performed before the nitriding treatment. It can be also seen from Figure 1 that for all studied conditions sensitization is not verified, suggesting the non-occurrence of chromium nitride precipitation. This assumption is in agreement with the XRD results presented in Figure 2. In addition, according to Rolinski ${ }^{17}$, there is no chromium nitride formation in austenitic stainless steels plasma nitrided at low temperatures (usually below $450{ }^{\circ} \mathrm{C}$ ), which is attributed to the fact that in such conditions, chromium diffusion is negligible so that the chromium nitrides formation is inhibited ${ }^{18}$.

$\mathrm{X}$-ray diffraction patterns of untreated and plasma nitrided sample surfaces for different nitriding temperatures are shown in Figure 2. Results indicate that the original peaks of austenite phase $(\gamma-\mathrm{Fe})$ exhibit a displacement to the left, id. est towards lower $2 \theta$ angles, suggesting an austenite lattice expansion by the nitrogen introduced in solid solution during nitriding the nitrogen-expanded austenite $\left(\gamma_{N}\right)$ formation. Similar results were observed by ${ }^{19-23}$, for the nitriding of wrought AISI 316L stainless steel, and by ${ }^{24}$, for sintered AISI 316L stainless steel. In addition, Borgioli ${ }^{25}$ showed that the formation of the $\gamma_{N}$ phase also occurs during plasma nitriding and nitrocarburizing of sintered AISI 316L steel preformed at $773 \mathrm{~K}\left(500^{\circ} \mathrm{C}\right)$ and 8 hours. 


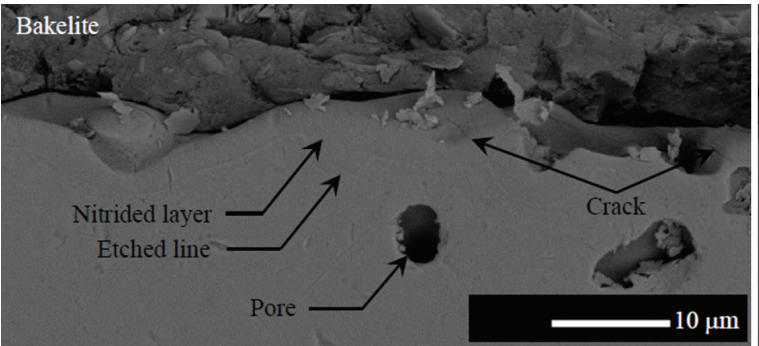

(a)

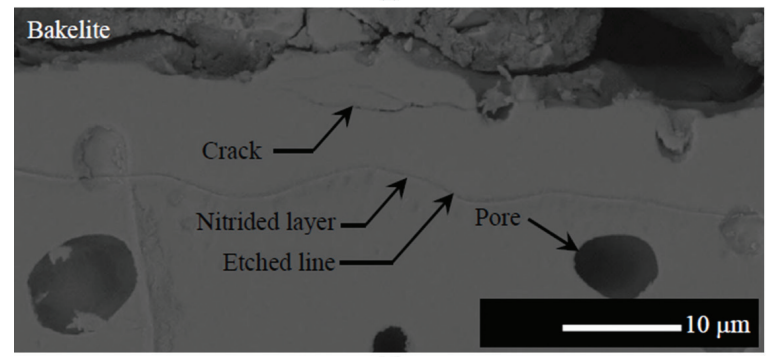

(c)
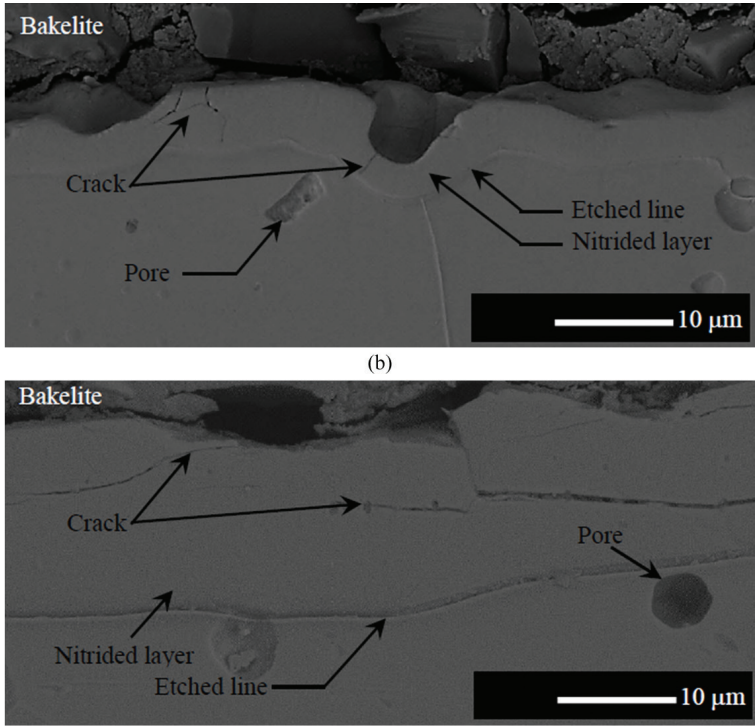

(d)

Figure 1. Cross-section micrographs of samples plasma nitrided at: (a) 350; (b) 380; (c) 410; and (d) $440{ }^{\circ} \mathrm{C}$. Treatments carried out for $8 \mathrm{~h}$, using a gas mixture composition of $60 \% \mathrm{~N}_{2}+20 \% \mathrm{H}_{2}+20 \% \mathrm{Ar}$, at a flow rate of $5.00 \times 10^{-6} \mathrm{Nm}^{3} \mathrm{~s}^{-1}$, and pressure of $800 \mathrm{~Pa}$.

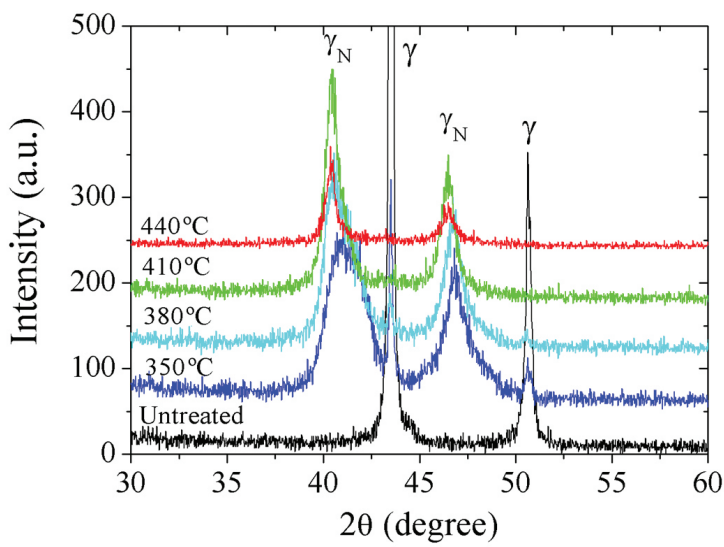

Figure 2. XRD patterns for untreated surface and surfaces treated at $350,380,410$ and $440{ }^{\circ} \mathrm{C}$. Treatments carried out for $8 \mathrm{~h}$, using a gas mixture composition of $60 \% \mathrm{~N}_{2}+20 \% \mathrm{H}_{2}+20 \%$ Ar, at a flow rate of $5.00 \times 10^{-6} \mathrm{Nm}^{3} \mathrm{~s}^{-1}$, and pressure of $800 \mathrm{~Pa}$.

Through Figure 2 results, it is also shown that for the lower nitriding temperatures $\left(350\right.$ and $\left.380^{\circ} \mathrm{C}\right)$, besides the nitrogen-austenite expanded phase peaks, the XRD patterns also indicate the presence of original austenite peaks $\gamma$-Fe (111) and $\gamma$-Fe (200). This is possibly associated with the depth achieved by the X-rays beam ${ }^{20}$, since, to the respective experimental conditions, the obtained thinner nitrided layers allow the passage of X-rays beam through and through, revealing in addition the original substrate structure.

Finally, the XRD patterns of Figure 2 for all the studied conditions evidence that there is no $\mathrm{CrN}$ precipitate formation. Such result deserves special attention since it is a strong indicative that the corrosion resistance of the nitrided samples at least would be maintained similar to that observed for the samples in the as-sintered condition.
But additional efforts comprising corrosion testing of treated samples are necessary to elucidate this point, which will be discussed ahead in another work. In addition, the formation of chromium nitride phases $\left(\mathrm{CrN}\right.$ and/or $\left.\mathrm{Cr}_{2} \mathrm{~N}\right)$ is expected at temperatures equal or higher than $450{ }^{\circ} \mathrm{C}$, condition that infers chromium diffusion enough to promote phase precipitation ${ }^{25}$. According to Williamson et al. ${ }^{26}$, chromium nitride precipitation in AISI 316 austenitic stainless steel samples plasma nitrided at $350{ }^{\circ} \mathrm{C}$ occurs after 2.5 days, and at a temperature of $450{ }^{\circ} \mathrm{C}$ only after 5 hours. The fact that chromium nitride precipitation did not occur for nitriding temperature below $440{ }^{\circ} \mathrm{C}$ in the present study may be explained by the difference of the activation energy for nitrogen and chromium diffusion in austenite. At low temperatures, nitrogen (interstitial atom) requires lower activation energy to diffuse, contrarily to the verified for chromium (substitutional atom), explaining the non-formation of $\mathrm{CrN}$ stable nuclei in the nitrogen-expanded austenite matrix.

Hardness measurements performed on the sample top (exposed to plasma) and bottom (non-exposed to plasma) surfaces treated at different nitriding temperatures are shown in Figure 3. As expected, the hardness values increase for higher nitriding temperature. Values of 695, 948, 1072 and $1343 \mathrm{HV}_{0.025}$ were obtained for temperatures of 350, 380, 410 and $440{ }^{\circ} \mathrm{C}$, respectively. On the other hand, the hardness of the non-nitrided surface was about $130 \mathrm{HV}_{0.025}$ for all studied conditions. The nitride surface hardness increase is directly related to nitrogen content in the expanded austenite, allied to the thicker layers obtained as the treatment temperature is increased. For the case of treatments carried out at lower temperatures, the resulting nitrided layer presents smaller thickness, and the indicated value is probably an apparent hardness as a consequence of the substrate bulk effect. Likewise, as stated by Borgoli et al. ${ }^{25}$, the porosity of sintered materials strongly influences hardness measurements. In 
general, the sintered sample apparent hardness is about 2 to 2.5 times smaller than the actual hardness, for the use of high indentation loads ${ }^{25}$. Confronting the top and bottom hardness values for samples nitrided at 350, 380, 410 and $440^{\circ} \mathrm{C}$, the treatment leads to a hardness increment of 5.3, 6.1, 7.7, and 8.1 times, respectively. These values are consistent with reported measurements in other works ${ }^{27,28}$, keeping in mind that Borgioli et al. ${ }^{25}$ indicate hardness values for sintered AISI 316L stainless steel 2.5 times lower than the wrought one.

Figure 4 presents the hardness measurement values performed on the sample top (exposed to plasma) and bottom (non-exposed to plasma) surfaces treated at different nitriding times. As verified in Figure 3 results, the hardness increase with treatment time is not pronounced as to the observed by increasing the nitriding temperature. Hardness values of 860,948 , and $991 \mathrm{HV}_{0.025}$ were obtained for surfaces nitrided during 4, 8, and 16 hours, respectively. The hardness increase (compared with the untreated material hardness) can be attributed both to the high nitrogen contents present in the expanded austenite solid solution, as confirmed by XRD patterns shown in Figure 5; and to the greater nitrided layer thickness, due to the same reason explained previously.

Figure 5 shows the XRD patterns of the samples surface nitrided at different treatment times. The results are similar to the obtained in the nitriding temperature study, as previously shown in Figure 2. For all the nitriding times, the original austenite phase peaks were displaced to the left, id. est, to smaller $2 \theta$ angles, confirming the increment of the austenite crystalline lattice parameter, due to the presence of high nitrogen contents in solid solution. Likewise, it is evidenced that the longer the nitriding time the more pronounced is the displacement of the peaks to smaller $2 \theta$ angles.

Finally, Figure 6 shows the cross section micrographs of samples treated at $380{ }^{\circ} \mathrm{C}$ for 4,8 and 16 hours. Results indicate that the nitrided layer thickness increases for longer nitriding times. Just as shown in the previous series (nitriding temperature study), there is no evidence of $\mathrm{CrN}$ precipitation occurrence for surfaces treated at different nitriding times. Nitrided layer thickness on the order of $1.8 \pm 0.19,4.3 \pm 0.29$ and $6.3 \pm 0.37 \mu \mathrm{m}$ was verified for surfaces treated for 4,8 and 16 hours, respectively.

\subsection{Nitrided layer growth kinetics}

Arrhenius plot of the nitrided layer thickness is presented in Figure 7. The point linearity indicates that atomic diffusion is probably the predominant mass transfer mechanism to the plasma nitriding treatment of sintered PIM 316L stainless steel, under the studied conditions, being the most important factor for the nitrided layer growth. From the Arrhenius-type behavior for the referred data, an activation energy for nitrogen diffusion of $111.4 \mathrm{kJmol}^{-1}$ was estimated (a detailed description of the activation energy determination method is presented in Scheuer et al. ${ }^{29}$ ). This value is equivalent to those of 110.73 and $110.49 \mathrm{kJmol}^{-1}$ obtained from the data presented by $\operatorname{Sun}^{30}$ for the plasma carburizing kinetics of AISI 316L and AISI 304L stainless steels, respectively; and higher than that estimated value of

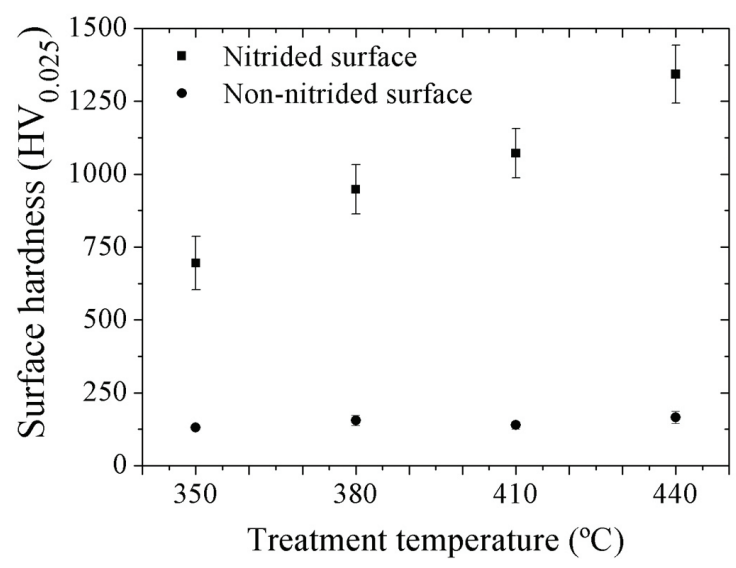

Figure 3. Surface hardness of the sample top (exposed to plasma -nitrided) and bottom (non-exposed to plasma-non-nitrided) obtained at $350,380,410$ and $440{ }^{\circ} \mathrm{C}$. Treatments carried out for $8 \mathrm{~h}$, using a gas mixture composition of $60 \% \mathrm{~N}_{2}+20 \% \mathrm{H}_{2}+20 \% \mathrm{Ar}$, at a flow rate of $5.00 \times 10^{-6} \mathrm{Nm}^{3} \mathrm{~s}^{-1}$, and pressure of $800 \mathrm{~Pa}$.

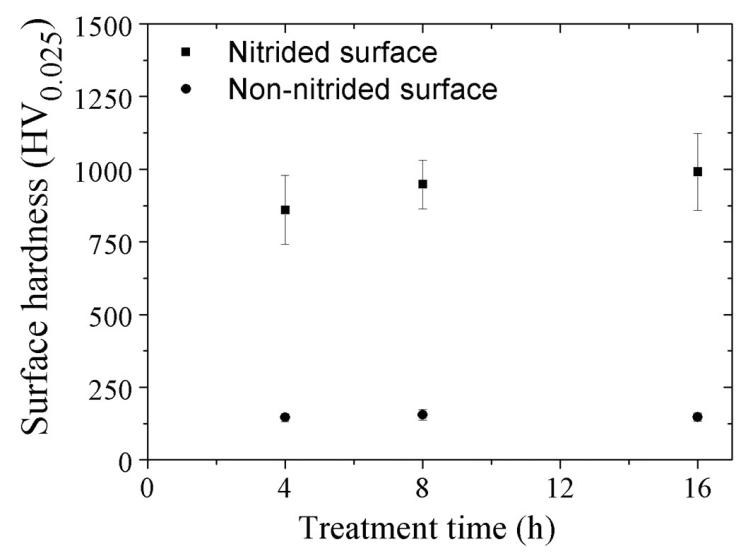

Figure 4. Surface hardness of the sample top (exposed to plasma -nitrided) and bottom (non-exposed to plasma-non-nitrided) obtained at 4,8 , and $16 \mathrm{~h}$. Treatments carried out at $380{ }^{\circ} \mathrm{C}$, using a gas mixture composition of $60 \% \mathrm{~N}_{2}+20 \% \mathrm{H}_{2}+20 \% \mathrm{Ar}$, at a flow rate of $5.00 \times 10^{-6} \mathrm{Nm}^{3} \mathrm{~s}^{-1}$, and pressure of $800 \mathrm{~Pa}$.

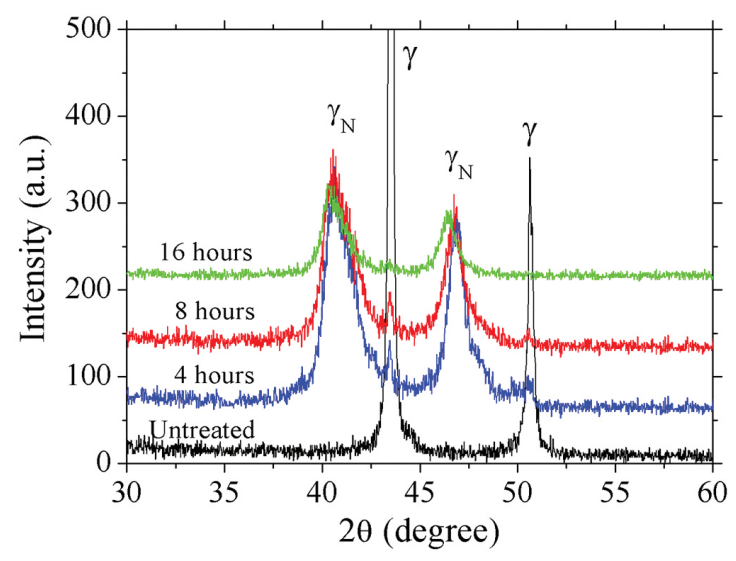

Figure 5. XRD patterns for untreated surfaces and surfaces treated at 4,8 and 16 hours. Treatments carried out at $380{ }^{\circ} \mathrm{C}$, using a gas mixture composition of $60 \% \mathrm{~N}_{2}+20 \% \mathrm{H}_{2}+20 \% \mathrm{Ar}$, at a flow rate of $5.00 \times 10^{-6} \mathrm{Nm}^{3} \mathrm{~s}^{-1}$, and pressure of $800 \mathrm{~Pa}$. 


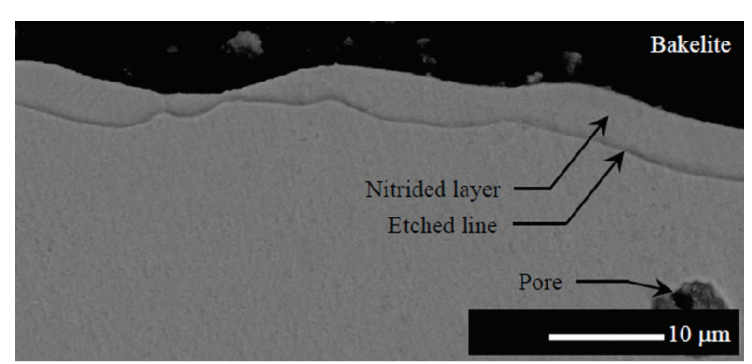

(a)

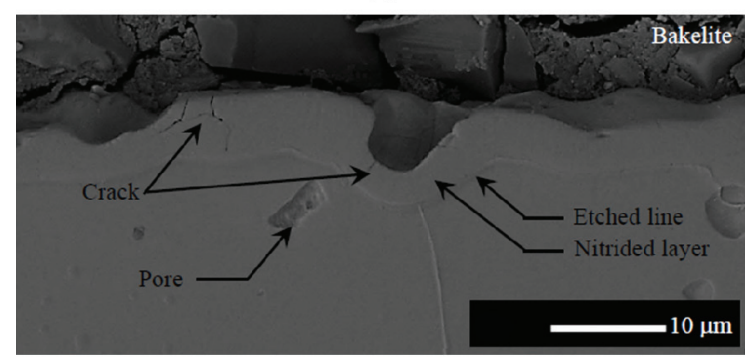

(b)

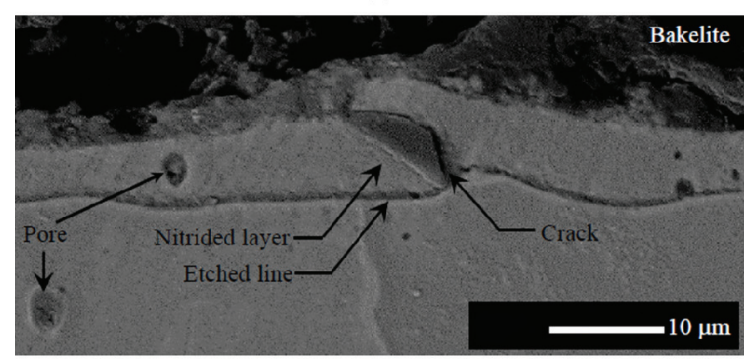

(c)

Figure 6. Cross-section micrographs of samples plasma nitrided for: (a) 4; (b) 8; and (c) $16 \mathrm{~h}$. Treatments carried out at $380{ }^{\circ} \mathrm{C}$, using a gas mixture composition of $60 \% \mathrm{~N}_{2}+20 \% \mathrm{H}_{2}+20 \% \mathrm{Ar}$, at a flow rate of $5.00 \times 10^{-6} \mathrm{Nm}^{3} \mathrm{~s}^{-1}$, and pressure of $800 \mathrm{~Pa}$.

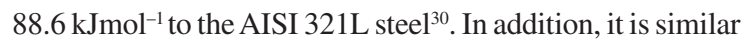
to the value of $107 \mathrm{kJmol}^{-1}$ presented by Menthe and $\mathrm{Rie}^{31}$ for the plasma nitriding of AISI 304L steel. It is to be noted that all the above-mentioned substrate materials are strictly stainless steels, presenting normally high $\mathrm{Cr}$ and $\mathrm{Ni}$ contents, which explains the similarity of the activation energy values obtained by $\operatorname{Sun}^{30}$ with the findings of the present work. By confronting such results, it is also evidenced that the difference between the wrought and sintered material does not influence the treatment kinetics, since the treated layer thickness is much smaller than the pores mean free path. So, in this case, the porosity of the sintered material can be disregarded in the estimation of the activation energy for the nitrogen diffusion.

On the other hand, the evolution of the nitrided layer thickness as a function of the square root of treatment time is presented in Figure 8. It was observed a linear relationship between the data points, which according to $\operatorname{Sun}^{30}$ constitutes a typical behavior for plasma assisted treatments, observed for most the investigated temperatures and times. Results of the Figure 8 confirm the atomic diffusion domain on the nitrided layer growth. Finally, it is to be noted that the fitted

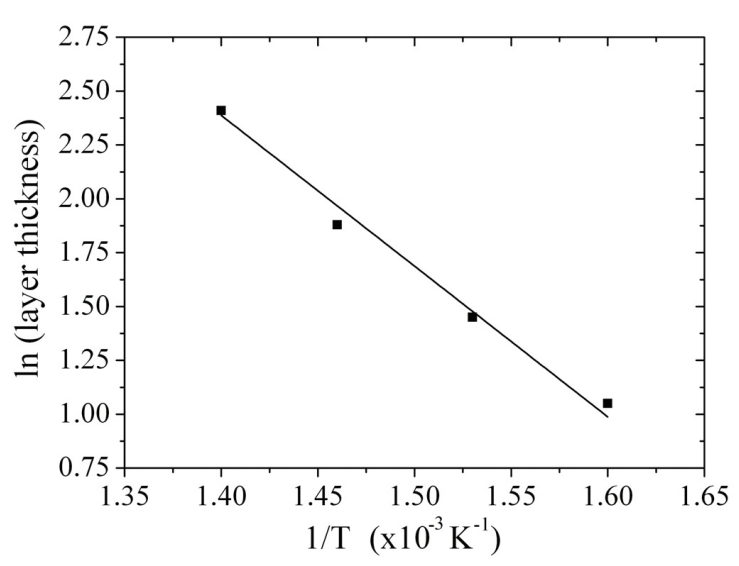

Figure 7. Arrhenius plot of the nitrided layer thickness for samples treated at $350,380,410$ and $440{ }^{\circ} \mathrm{C}$. Treatments carried out for $8 \mathrm{~h}$, using a gas mixture composition of $60 \% \mathrm{~N}_{2}+20 \% \mathrm{H}_{2}+20 \% \mathrm{Ar}$, at a flow rate of $5.00 \times 10^{-6} \mathrm{Nm}^{3} \mathrm{~s}^{-1}$, and pressure of $800 \mathrm{~Pa}$.

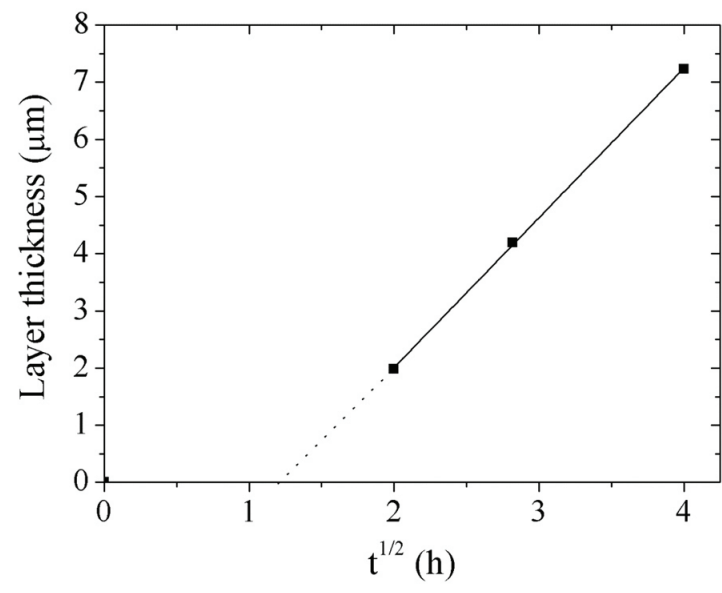

Figure 8. Evolution of the nitrided layer thickness as a function of the square root of treatment time. Treatments carried out at $380{ }^{\circ} \mathrm{C}$, using a gas mixture composition of $60 \% \mathrm{~N}_{2}+20 \% \mathrm{H}_{2}+20 \% \mathrm{Ar}$, at a flow rate of $5.00 \times 10^{-6} \mathrm{Nm}^{3} \mathrm{~s}^{-1}$, and pressure of $800 \mathrm{~Pa}$.

line of the Figure 8 does not intersect the origin point ( $\mathrm{x}=0$, $y=0)$ of the graphic, indicating that the treatment presents an initial period of incubation for the layer formation. One possible explanation for the incubation time would be that the adopted plasma sputter-cleaning stage was not efficient in removing the native oxide layer on the sample surface. Thus, it can be stated that for the initial treatment periods, no nitrided layer formation/growth occurs if the oxide layer is present on the substrate surface.

\subsection{Nitrided surface characterization}

For comparison purposes, Figure 9 shows SEM images of the samples surface before (as-sintered) and after nitriding treatment, for nitriding temperatures of 350, 380, 410, and $440{ }^{\circ} \mathrm{C}$. Crack formation in regions adjacent to pores (highlighted by arrows in Figure 9) can be observed. In addition, it is possible to verify that the occurrence of cracks is intensified for higher nitriding temperatures. It is to be 

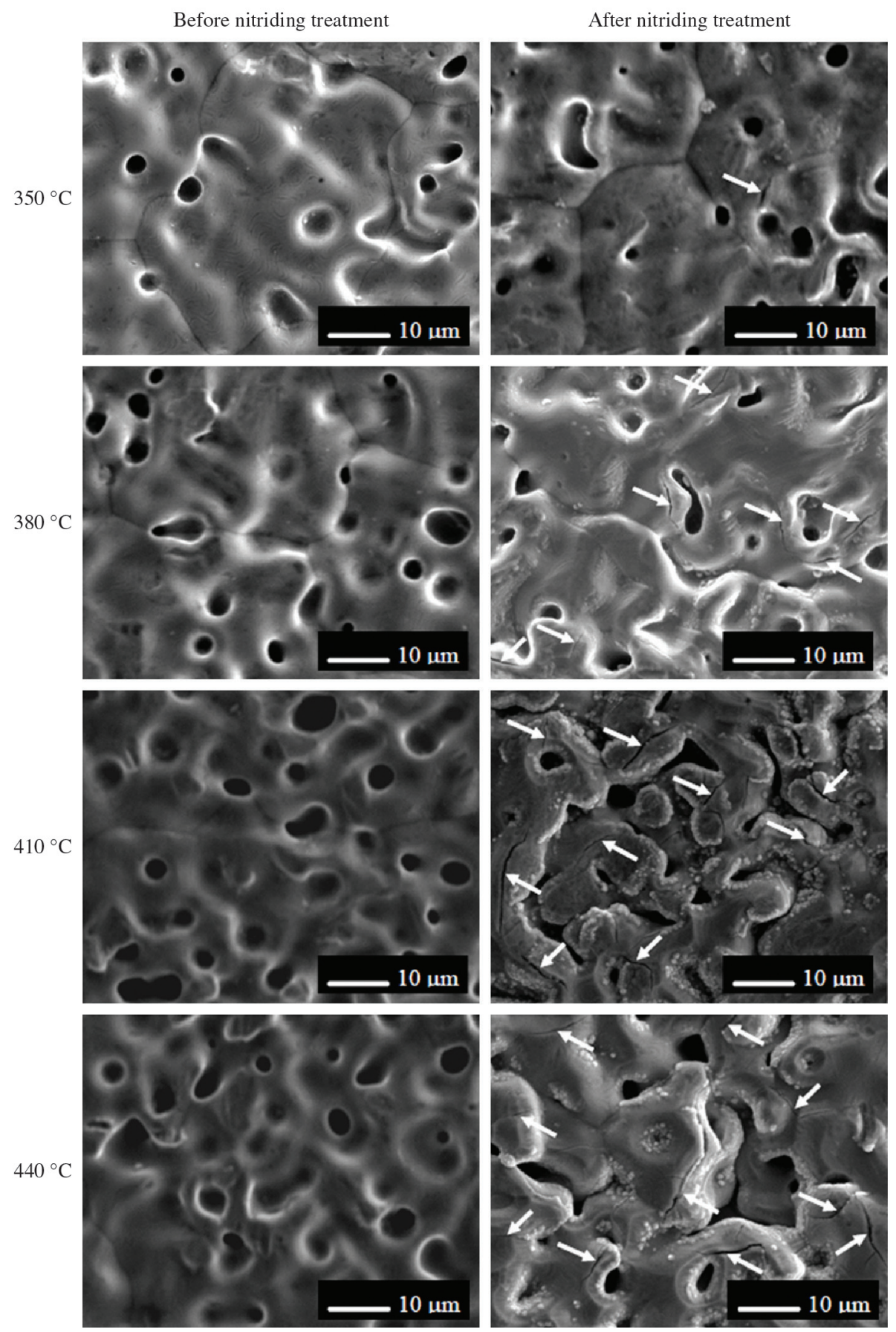

Figure 9. SEM images of the samples surface before (as-sintered) and after (as-nitrided) treatment, for different nitriding temperatures of $350,380,410$, and $440{ }^{\circ} \mathrm{C}$. Treatments carried out for $8 \mathrm{~h}$, using a gas mixture composition of $60 \% \mathrm{~N}_{2}+20 \% \mathrm{H}_{2}+20 \% \mathrm{Ar}$, at a flow rate of $5.00 \times 10^{-6} \mathrm{Nm}^{3} \mathrm{~s}^{-1}$, and pressure of $800 \mathrm{~Pa}$.

noted that this result was not expected considering that the substrate material is an austenitic stainless steel and its f.c.c. crystalline structure is characteristically ductile. A possible explanation to crack formation would be related to the strong residual stresses developed on the treated surfaces due to presence of nitrogen expanding the austenite crystalline lattice parameter. As previously discussed, it is expected that the higher the nitriding temperature the higher is the nitrogen content of the nitrided layer, since the nitrogen diffusion coefficient is also increased. So, in this case, higher stress levels tend to be created in the nitrided layer, leading to a more intense effect of crack formation. The mechanism for which the crack is formed is not clear to the authors of the present work, being necessary additional efforts to explain 
how the stress-relief process occurs in the present case, leading to the crack opening.

It can be also verified in Figure 9 that the surface morphology of the samples in the as-sintered condition is characterized by a "smooth" appearance, which is not observed after treatment. By analyzing the nitrided surface images, formation of sub-micrometric like-particles can be observed specially for higher nitriding temperatures, in the case 410 and $440{ }^{\circ} \mathrm{C}$. Such particles are probably a result of the redeposition of metal atoms sputtered from the surface, leading supposedly to the nucleation of small nitride particles at the surface. Some important points can be mentioned to justify this assumption. First, it should be noted that the redeposition occurs preferentially in the pores vicinity, since these regions present favorable thermodynamic conditions to condensation ${ }^{2}$. Another important aspect would be the increase of the redeposition rate for higher temperatures. It is to be remembered that the treatment is performed without auxiliary heating (hot wall) system. So, to obtain higher temperatures, the time switched-on of the pulse $\left(t_{o n}\right)$ should be higher, resulting in more intense sputtering effect, which allied to the utilized gas pressure, leads to a higher rate of redeposition.

In the same way, for comparison purposes, Figure 10 shows SEM images of the samples surface before (as-sintered) and after nitriding treatment, for nitriding times of $4,8,16$ hours. The results also show cracking formation in adjacent regions of the pores. Similarly, it is possible to verify that the occurrence of cracks is intensified for longer nitriding times. As expected for thermally activated process, the longer the nitriding time the higher would be the residual stresses developed on the treated surfaces due to the presence of a higher amount of nitrogen expanding the austenite crystalline lattice parameter. As discussed in the Figure 9 results, the treated surfaces for longer nitriding times also show the formation of sub-micrometer particles, due to the redeposition process of sputtered metal atoms from the surface. An increase to the particles amount is
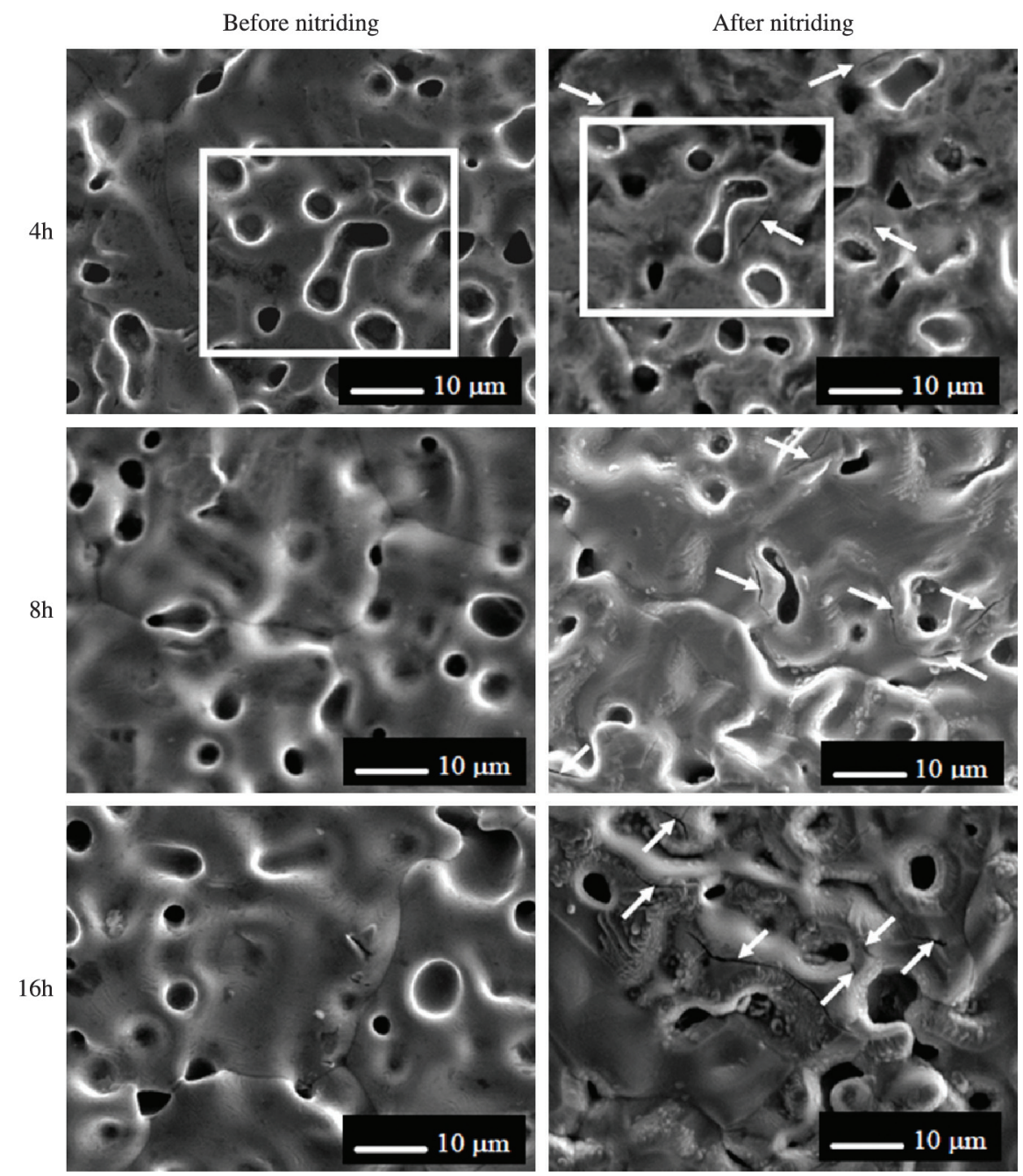

Figure 10. SEM images of the samples surface before (as-sintered) and after (as-nitrided) treatment, for nitriding times of 4, 8, 16 hours. Treatments carried out at $380{ }^{\circ} \mathrm{C}$, using a gas mixture composition of $60 \% \mathrm{~N}_{2}+20 \% \mathrm{H}_{2}+20 \% \mathrm{Ar}$, at a flow rate of $5.00 \times 10^{-6} \mathrm{Nm}^{3} \mathrm{~s}^{-1}$, and pressure of $800 \mathrm{~Pa}$. 
verified for longer treatment times, which confirms the assumption previously presented.

Finally, the observation of the surface morphology obtained for a sample before and after $4 \mathrm{~h}$ nitriding (see Figure 10), for a strictly identical region as shown by a white-line delineated area, indicates a tendency of Ferret diameter decrease after nitriding treatment for some pores and Ferret diameter increase for other pores. The referred increase could be explained by a higher sputtering rate next to the pore boundaries present at the surface, when compared with that verified to the flat surface presenting no pore. Based on this result, no assertion indicating the nitriding process as an efficient pore sealing treatment can be made, despite the several arguments showing the contrary, such as: a) the obtainment of nitrogen-expanded austenite; b) intensification of the sputtering effect for higher nitriding temperatures and longer nitriding times; c) by incrementing the mass transport mechanism in the vapor phase, comprising intense backscattering of sputtered atoms at the utilized gas pressure, and consequent redeposition next to the sintering necks. It is to be noted that such effects occurring in a conjugated form would tend to promote pore constriction, resulting in a reduced dimension of the pores. The data comparison of Ferret diameter of the pores, present in both the surfaces prior and after nitriding (results not shown), aiming to determine the efficiency of the nitriding process as a pore sealing treatment was not conclusive. It was due to great difficulty of mapping exactly the same region of the sample, considering the sample demarcation procedure adopted in the present work. In this case, based on the above-mentioned aspects, additional efforts are necessary aiming to elucidate the efficiency of the nitriding process as a pore sealing treatment.

\section{Conclusion}

Experiments were carried out aiming to determine the influence of the treatment temperature and time on the process kinetics, microstructure and surface characteristics of the low-temperature plasma nitriding in sintered PIM 316L stainless steel, and the main conclusions of the work can be listed as follows:

\section{References}

1. De Souza SD, Olzon-Dionysio M, Miola EJ and PaivaSantos CO. Plasma nitriding of sintered AISI 316L at several temperatures. Surface and Coatings Technology. 2004; 184:176181. http://dx.doi.org/10.1016/j.surfcoat.2003.11.007

2. Maliska AM, De Oliveira AM, Klein AN and Muzart JLR. Surface porosity sealing effect of plasma nitrocarburizing on sintered unalloyed iron. Surface and Coatings Technology. 2001; 141:128-134. http://dx.doi.org/10.1016/ S0257-8972(01)01016-7

3. Hombeck F and Bell T. Environmentally harmless plasma thermochemical processes. Surface Engineering. 1991; 7(1):4552. http://dx.doi.org/10.1179/sur.1991.7.1.45

4. Tosic MM, Tersic I and Gligorijevic R. Plasma nitriding of powder metal steel. Vacuum. 1990; 40(1):131-134. http:// dx.doi.org/10.1016/0042-207X(90)90137-N
- Low-temperature plasma nitriding can be successfully applied to improve surface hardness of sintered PIM $316 \mathrm{~L}$ stainless steel, which is due to the formation of nitrogen-expanded austenite $\left(\gamma_{\mathrm{N}}\right)$. The results showed that treatment time does not exert great influence on the material hardness increase;

- The kinetics of the nitrided layer growth depends on treatment temperature and time. From the presented results, it can be concluded that low-temperature nitriding is a diffusion controlled process. The calculated activation energy for nitrogen diffusion is $111.4 \mathrm{kJmol}^{-1}$;

- At least to the studied conditions, XRD patterns indicate that the nitrided layer is constituted by nitrogen-expanded austenite $\left(\gamma_{N}\right)$, being that no chromium and iron nitride formation was observed in the obtained layers. What is confirmed by cross section micrographs where no sensitization can be observed;

- Crack formation is evidenced in the regions adjacent to pores, for all studied conditions, and an increase tendency in the cracks number is observed for higher nitriding temperatures and longer treatment times. This effect is possibly related to the stress-relief effect around the pores, as a result of the high stress levels obtained from $\gamma_{\mathrm{N}}$ formation, but the mechanism for which stress-relief occurs is to be explained in future work.

\section{Acknowledgments}

This work was supported by CNPq Brazilian Agency and PRH-24 (UFPR). The authors would like also to acknowledge to the Laboratory of Minerals and Rocks Analysis - LAMIR, and to the Laboratory of X-ray Optics and Instrumentation - LORXI, both the laboratories from the Universidade Federal do Paraná (UFPR), by the availability of SEM and X-ray diffraction equipment's use.

5. Rembges W. Plasma nitriding of PM parts. Metal Powder Report. 1988; 43(11):765-768.

6. Dawes C, Tranter DF and Smith CG. Reappraisal of nitrocarburising and nitriding when applied to design and manufacture of non-alloy steel automobile components. Metals Technology. 1979; 6(9):345-353. http://dx.doi. org/10.1179/030716979803276390

7. Borges PC, Martinelli AE and Franco CV. Microstructure and corrosion behaviour of plasma-nitrocarburized sintered steel. Materials and Corrosion. 2004; 55(8):594-601. http://dx.doi. org/10.1002/maco.200303784

8. Neto JPA, Giacomelli C, Klein NA, Muzart JLR and Spinelli A. Characterization of Sintered and Sintered/Plasma-Nitrided Fe1.5\% Mo Alloy by SEM, X-Ray Diffraction and Electrochemical Techniques. Materials Research. 2002; 5(2):165-172. 
9. Bell T. Surface treatment and coating of $\mathrm{P} / \mathrm{M}$ components. Powder Metallurgy. 1991; 34(4):253-258. http://dx.doi. org/10.1179/pom.1991.34.4.253

10. Sun Y, Bell T. Plasma surface engineering of low alloy steel. Materials Science and Engineering: A. 1991; 40:419-434. http://dx.doi.org/10.1016/0921-5093(91)90458-Y

11. Zhang ZL, Bell T. Structure and corrosion resistance of plasma nitrided stainless steel. Surface Engineering. 1985; 1(2):131136. http://dx.doi.org/10.1179/sur.1985.1.2.131

12. Dong H. S-phase surface engineering of $\mathrm{Fe}-\mathrm{Cr}, \mathrm{Co}-\mathrm{Cr}$ and Ni-Cr alloys. International Materials Reviews. 2010, 55:6598. http://dx.doi.org/10.1179/095066009X12572530170589

13. Sun $Y$ and Bell T. Dry sliding wear resistance of low temperature plasma carburized austenitic stainless steel. Wear. 2002; 253:689-693. http://dx.doi.org/10.1016/S00431648(02)00170-9

14. Lo KH, Shek CH and Lai JKL. Recent developments in stainless steels. Materials Science and Engineering R. 2009; 65:39-104. http://dx.doi.org/10.1016/j.mser.2009.03.001

15. Allenstein AN, Lepienski CM, Buschinelli AJA and Brunatto SF. Plasma Nitriding of CA-6NM Steel: Effect of $\mathrm{H}_{2}+\mathrm{N}_{2}$ Gas Mixtures in Nitride Layer Formation for Low $\mathrm{N}_{2}$ Contents at $500{ }^{\circ} \mathrm{C}$. Materials Research. 2010; 13(4):1-6. http://dx.doi. org/10.1590/S1516-14392010000400020

16. Czerwiec T, He H, Weber S, Dong $\mathrm{C}$ and Michel H. On the occurrence of dual diffusion layers during plasma-assisted nitriding of austenitic stainless steel. Surface and Coating Technology. 1998; 200(18-19):5289-5295. http://dx.doi. org/10.1016/j.surfcoat.2005.06.014

17. Rolinski E. Effect of Plasma Nitriding Temperature on Surface Properties of Austenitic Stainless Steel. Surface Engineering. 1987; 3(1):35-40. http://dx.doi.org/10.1179/ sur.1987.3.1.35

18. Lei MK and Zhang ZL. Plasma source ion nitriding: a new low-temperature, low-pressure nitriding approach. Journal of Vacuum Science and Technology A. 1995; 13:2986-2990. http:// dx.doi.org/10.1116/1.579625

19. Asgari M, Barnoush A, Johnsen R and Hoel R. Microstructural characterization of pulsed plasma nitrided 316L stainless steel. Materials Science and Engineering A. 2011; 529:425-434. http://dx.doi.org/10.1016/j.msea.2011.09.055

20. Borgioli F, Fossati A, Galvanetto E and Bacci T. Glowdischarge nitriding of AISI 316L austenitic stainless steel: influence of treatment temperature. Surface \& Coatings Technology. 2005; 200:2474-2480. http://dx.doi.org/10.1016/j. surfcoat.2004.07.110

21. Borgioli F, Fossati A, Galvanetto E, Bacci T and Pradelli G. Glow-discharge nitriding of AISI 316L austenitic stainless steel: influence of treatment pressure. Surface \& Coatings
Technology. 2006; 200:5505-5513. http://dx.doi.org/10.1016/j. surfcoat.2005.07.073

22. Fossati A, Borgioli F, Galvanetto E and Bacci T. Glowdischarge nitriding of AISI 316L austenitic stainless steel: influence of treatment time. Surface \& Coatings Technology. 2006; 200:3511-3517. http://dx.doi.org/10.1016/j. surfcoat.2004.10.122

23. Gontijo LC, Machado R, Miola EJ, Casteletti LC, Alcântara NG and Nascente PAP. Study of the $S$ phase formed on plasmanitrided AISI 316L stainless steel. Materials Science and Engineering A. 2006; 431:315-321. http://dx.doi.org/10.1016/j. msea.2006.06.023

24. Bacci T, Borgioli F, Galvanetto E and Pradelli G. Glowdischarge nitriding of sintered stainless steels. Surface and Coatings Technology. 2001; 139:251-256. http://dx.doi. org/10.1016/S0257-8972(01)01010-6

25. Borgioli F, Galvanetto E, Bacci T and Pradelli G. Influence of the treatment atmosphere on the characteristics of glow discharge treated sintered stainless steels. Surface and Coatings Technology. 2002; 149:192-197. http://dx.doi.org/10.1016/ S0257-8972(01)01431-1

26. Williamson DL, Ozturk $\mathrm{O}$, Wei $\mathrm{R}$ and Wilbur PJ. Metastable phase formation and enhanced diffusion in f.c.c. alloys under high dose, high flux nitrogen implantation at high and low ion energies. Surface and Coatings Technology. 1994; 65:15-23. http://dx.doi.org/10.1016/S02578972(94)80003-0

27. Menthe E, Rie KT, Schultze JW and Simson S. Structure and properties of plasma-nitrided stainless steel. Surface \& Coatings Technology. 1995; 74-75:412-416. http://dx.doi. org/10.1016/0257-8972(95)08246-8

28. Marchev K, Cooper CV, Blucher JT and Giessen BC. Condition for the Formation of a Martensitic Single-phase Compound Layer in Ion-nitrided 316L Austenitic Stainless Steel. Surface and Coating Technology. 1998; 99:225-228. http://dx.doi. org/10.1016/S0257-8972(97)00532-X

29. Scheuer CJ, Cardoso RP, Mafra M and Brunatto SF. AISI 420 martensitic stainless steel low-temperature plasma assisted carburizing kinetics. Surface and Coating Technology. 2013; 214:30-37. http://dx.doi.org/10.1016/j. surfcoat.2012.10.060

30. Sun Y. Kinetics of low temperature plasma carburizing of austenitic stainless steels. Journal of Materials Processing Technology. 2005; 168:189-194. http://dx.doi.org/10.1016/j. jmatprotec.2004.10.005

31. Menthe E and Rie KT. Further investigation of the structure and properties of austenitic stainless steel after plasma nitriding. Surface and Coatings Technology. 1999; 116-119:199-204. http://dx.doi.org/10.1016/S0257-8972(99)00085-7 